\title{
Autoimmune and Paraneoplastic Channelopathies
}

\author{
Steven Vernino \\ Department of Neurology, University of Texas Southwestern Medical Center, Dallas, Texas, 75390-9036
}

\begin{abstract}
Summary: Thirty years ago, antibodies against the muscle acetylcholine receptor (AChR) were recognized as the cause of myasthenia gravis. Since then, there has been great interest in identifying other neurological disorders associated with autoantibodies. Several other antibody-mediated neuromuscular disorders have been identified, each associated with an antibody against a ligand- or voltage-gated ion channel. The Lambert-Eaton syndrome is caused by antibodies against voltagegated calcium channels and often occurs in patients with small cell lung cancer. Acquired neuromyotonia is caused by voltagegated potassium channel antibodies, and autoimmune autonomic ganglionopathy is caused by antibodies against the neuronal AChR in autonomic ganglia. There is good evidence that antibodies in these disorders cause changes in synaptic function or neuronal excitability by directly inhibiting ion channel func-
\end{abstract}

tion. More recently, studies have identified ion channel antibodies in patients with certain CNS disorders, such as steroidresponsive encephalitis and paraneoplastic cerebellar ataxia. It remains unclear if antibodies can gain access to the CNS and directly cause ion channel dysfunction. Treatment of autoimmune channelopathies includes drugs that help restore normal neuronal function and treatments to remove pathogenic antibodies (plasma exchange) or modulate the immune response (steroids or immunosuppressants). These disabling neurological disorders may be dramatically responsive to immunomodulatory therapy. Future studies will likely lead to identification of other ion channel antibodies and other autoimmune channelopathies. Key Words: Autoantibodies, antigenic modulation, neuromuscular junction, thymoma, lung cancer, pyridostigmine.

\section{INTRODUCTION}

Acquired changes in ion channel function are an important cause of neurological symptoms. Many pharmaceuticals (e.g., anticonvulsants) and toxins (e.g., snake and marine toxins) modulate nerve or muscle excitability through effects on ion channels. Autoimmune channelopathies are a group of neurological disorders associated with antibodies to specific ion channels on neurons or muscle. In these conditions, the specific antibodies are either known or presumed to have an inhibitory effect on ion channel function. Myasthenia gravis (MG) is the prototypical disorder, the first disease proven to be an antibody-mediated channelopathy. ${ }^{1}$ There is now a wide range of autoimmune channelopathies (Table 1), many of which were identified because of clinical similarities or clinical association with MG. Antibodies associated with these disorders can target either ligand-gated or voltagegated ion channels.

The mechanisms that initiate the production of auto-

Address correspondence and reprint requests to: Steven Vernino, $\mathrm{MD}, \mathrm{PhD}$, University of Texas Southwestern Medical Center, Department of Neurology, 5323 Harry Hines Blvd., Dallas, TX 75390-9036;

E-mail: steven.vernino@utsouthwestern.edu. antibodies remain a mystery in most cases. Viral or bacterial infection may trigger an autoimmune response against the nervous system in susceptible individuals. In other cases, neurological disorders occur as a remote (paraneoplastic) complication of systemic malignancy. These paraneoplastic neurological disorders appear to result from a specific autoimmune reaction initiated by the immune response against cancer. ${ }^{2}$ In some cases (especially with poorly differentiated small cell lung carcinoma, SCLC), the cancer cells express proteins that are usually restricted to the nervous system, including ligand- and voltage-gated ion channels. ${ }^{3,4}$ In other situations (i.e., thymoma or lymphoma), the malignancy may interrupt the maintenance of tolerance to self antigens. Many different neuron-specific autoantibodies have been described in association with the paraneoplastic neurological disorders. In most instances, these paraneoplastic autoantibodies are directed against intracellular antigens. These antibodies are useful diagnostic markers and are highly predictive of the presence and type of underlying cancer. However, they do not appear to have any direct pathogenic effects because these antibodies are unlikely to have access to the intracellular compartment in intact neurons. Further, there is no precise correlation between 
Table 1. Autoimmune Channelopathies

\begin{tabular}{lll}
\hline Ion channel & \multicolumn{1}{c}{ Disease(s) } & \multicolumn{1}{c}{ Symptoms } \\
\hline $\begin{array}{l}\text { Muscle }(\alpha 1) \text { nicotinic AChR } \\
\text { Ganglionic neuronal }(\alpha 3) \text { AChR }\end{array}$ & $\begin{array}{l}\text { Myasthenia gravis } \\
\text { Autoimmune autonomic ganglionopathy }\end{array}$ & $\begin{array}{l}\text { Weakness and muscle fatigue } \\
\text { Orthostatic hypotension, tonic pupils, } \\
\text { bladder retention, gastroparesis } \\
\text { Muscle weakness }\end{array}$ \\
$\begin{array}{ll}\text { Voltage-gated calcium channel } \\
\text { (P/Q-type) }\end{array}$ & $\begin{array}{l}\text { Lambert-Eaton syndrome } \\
\text { Ataxia (patients with small cell cancer) }\end{array}$ \\
$\begin{array}{ll}\text { Voltage-gated potassium channel } \\
\text { (Kv1.1, 1.2, 1.6) }\end{array}$ & $\begin{array}{l}\text { Acquired neuromyotonia } \\
\text { Limbic encephalitis }\end{array}$ & $\begin{array}{l}\text { Muscle twitching, cramps, hyperhidrosis } \\
\text { Amnesia, seizures, personality changes }\end{array}$ \\
GluR3 (AMPA receptor) & Morvan's syndrome & Neuromyotonia, insomnia, hallucinations \\
NR2 (NMDA receptor) & Rasmussen's encephalitis & Intractable epilepsy, cognitive decline
\end{tabular}

$\mathrm{AChR}$, acetylcholine receptors.

the nuclear or cytoplasmic antibodies and particular associated neurological syndromes.

Unlike the traditional paraneoplastic autoantibodies, antibodies against ion channels are directed against extracellular determinants of membrane proteins. These antibodies therefore have the potential to produce direct pathogenic effects by binding to and modifying the function of these membrane proteins in vivo. As a consequence, each ion channel antibody is more likely to be associated with particular neurological syndromes. Ion channel antibodies may be a paraneoplastic phenomenon in some patients, but the majority of patients with ion channel antibodies do not have cancer.

Antibodies against ion channels are difficult to detect using standard immunoblot, ELISA, or immunohistochemical techniques. Most membrane ion channels have a restricted distribution and are not abundant. The antibodies are typically specific for native conformations of the channel and do not bind to denatured proteins or peptides. Therefore, ion channel antibody assays typically involve immunoprecipitation of radiolabeled ion channels in detergent-extracted membrane preparations.

The association of a serum autoantibody with a particular neurological disorder is only one piece of evidence to define antibody-mediated disorders. Additional criteria are replication of characteristic features of the disease in an animal model (using either passive administration of human antibody or active immunization with the antigen) and demonstration that the human disease improves after removal of circulating antibody (i.e., plasma exchange). ${ }^{1,5} \mathrm{MG}$ is the best example of a neurological disease that fully meets these criteria. Of the other identified autoimmune channelopathies, those associated with peripheral nervous system disorders are most likely to be antibody-mediated disorders. The ability of ion channel antibodies to cross the blood-brain barrier to cause CNS dysfunction remains to be proven in humans or experimental animals.

\section{Muscle nicotinic acetylcholine receptor antibodies}

Nicotinic acetylcholine receptors (AChR) are cationselective ion channels gated by the binding of acetylcholine and are formed by the radial association of five subunits to form a membrane complex with a central ion channel pore. Different types of nicotinic AChR are found throughout the central and peripheral nervous system. Transmission at the neuromuscular junction is mediated by densely clustered $\mathrm{AChR}$ on the muscle endplate. The muscle AChR is formed by the association of two AChR $\alpha 1$ subunits with $\beta 1, \delta$, and $\epsilon$ (or fetal $\gamma$ ) subunits. Mutations in the muscle AChR subunit genes are either lethal or cause congenital disorders of neuromuscular junction transmission (see Engel $^{6}$ ).

Myasthenia gravis. Antibodies against muscle AChR cause the clinical and electrophysiologic deficits in MG. Patients with MG develop fatigable muscle weakness that affects the ocular and proximal limb muscles prominently. Ptosis and diplopia are common symptoms. In severe cases, dysphagia and respiratory weakness can be life-threatening complications. Antibodies against the skeletal muscle AChR are found in $80 \%$ to $85 \%$ of patients with generalized MG and in 50\% to $60 \%$ of those with symptoms limited to the eyes. ${ }^{1}$ The clinical diagnosis of MG depends on the history of variable weakness without sensory disturbance, electrophysiologic evidence of defective neuromuscular junction transmission (using repetitive motor nerve stimulation, FIG. 1; or single-fiber electromyography), and the presence of circulating muscle AChR antibodies.

About $15 \%$ of patients with adult-onset MG have thymoma (a histologically benign, but locally invasive, tumor of the anterior mediastinum). Thymoma is also associated with numerous other autoimmune disorders. One-third of patients with thymoma present with MG, and muscle AChR antibodies can be found in $30 \%$ to $40 \%$ of patients with thymoma who do not have any signs of $\mathrm{MG}^{7}$

In MG, antibodies bind to the muscle $\mathrm{AChR}$ and re- 

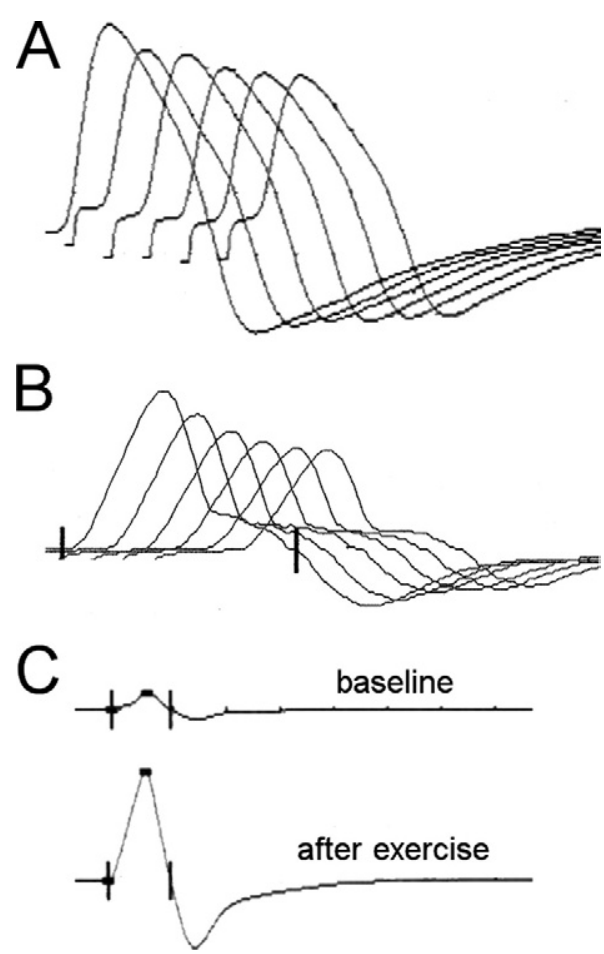

FIG. 1. Electrophysiological findings in myasthenia gravis (MG) and Lambert-Eaton syndrome. Recording of compound muscle action potential (CMAP) during repetitive stimulation of motor nerves is an important method for identifying disorders with defective neuromuscular junction (NMJ) transmission. In normal subjects, the CMAP amplitude remains very stable during repetitive stimulation. In MG, the CMAP amplitude is normal at rest but decreases during repeated stimulation at 2-3 Hz. This decrement results from a reduced safety margin for NMJ transmission and is the electrophysiologic correlate of muscle fatigue. (A) Recording of the accessory nerve CMAP during $3 \mathrm{~Hz}$ stimulation in MG patient. The CMAP amplitude decreases by $30 \%(2 \mathrm{mV}$ and $5 \mathrm{~ms}$ divisions). (B) In a patient with Lambert-Eaton syndrome (LES) the initial CMAP amplitude is reduced and decreases even further at low rates of repetitive stimulation. A $3 \mathrm{~Hz}$ stimulation produces a $36 \%$ decrement of the ulnar nerve CMAP ( $1 \mathrm{mV}$ and $2 \mathrm{~ms}$ divisions). (C) After brief exercise (or with high rates of nerve stimulation), the CMAP amplitude may dramatically increase. Shown is the ulnar nerve CMAP in a patient with LES recorded at rest and immediately after 10 seconds of exercise. The CMAP increases fourfold (5 mV divisions). This facilitation of NMJ transmission reflects accumulation of calcium in the motor nerve terminal, which temporarily restores transmitter release.

duce the number of functional AChR on the muscle endplate membrane principally by increasing the rate of receptor internalization and degradation (a process referred to as antigenic modulation). To a lesser extent, antibodies can also block the binding of acetylcholine. Detection of AChR binding antibodies is the most sensitive test for MG, but serologic tests for AChR modulating and blocking antibodies are also commercially available. Binding of antibodies to the AChR also leads to complement-mediated damage to the muscle membrane. Complement activation appears to be an important component of the pathophysiology of MG. The muscle endplate loses its elegant, folded structure and becomes simplified; AChR are reduced in number; receptors are no longer clustered, and the synaptic cleft widens. As a consequence, the amplitude of postsynaptic endplate potentials is reduced. This reduces the fidelity of neuromuscular transmission so that transmission may fail, particularly during periods of repeated muscle contraction.

Much of our understanding of antibody-mediated disorders has been derived from studies of animal models of MG (experimental autoimmune myasthenia gravis, EAMG). Animals immunized with muscle AChR proteins in adjuvant develop weakness and electrophysiologic evidence of neuromuscular transmission failure. ${ }^{8,9}$ EAMG can also be induced in animals by passive administration of immunoglobulin obtained from the serum of patients with MG. ${ }^{10}$

Symptomatic treatment of MG includes acetylcholinesterase inhibitors (e.g., pyridostigmine, edrophonium) which enhance neuromuscular junction transmission by slowing the breakdown of acetylcholine. These drugs improve the likelihood of successful neuromuscular transmission, improve strength, and reduce fatigability in MG patients. Patients must avoid medications that have inhibitory effects on neuromuscular junction transmission (especially those that inhibit AChR function) because these drugs may cause increased weakness. Such drugs include aminoglycoside antibiotics, neuromuscular blocking anesthetic agents (e.g., vecuronium), certain antiarrhythmic drugs, quinine, and others.

Definitive treatment for MG, and other antibody-mediated channelopathies, requires elimination of the pathogenic antibodies. Removal of serum antibodies can be accomplished by plasma exchange, which provides a rapid, but temporary, improvement in symptoms. Treatments that inhibit production of autoantibodies are also effective. These treatments include intravenous immunoglobulin, corticosteroids, and a variety of immunosuppressive drugs. Removal of the thymus (thymectomy) is also used to treat MG and is absolutely required in cases of thymoma. In current practice, the majority of MG patients can be managed effectively and have minimal disability.

\section{Ganglionic AChR antibodies}

The ganglionic nicotinic AChR mediates fast synaptic transmission in all peripheral autonomic ganglia (sympathetic, parasympathetic, and enteric ganglia). This AChR is homologous but genetically and immunologically distinct from the AChR at the neuromuscular junction. AChR on autonomic neurons are composed of two $\alpha 3$ subunits in combination with three $\beta$ subunits. These receptors are absolutely required for normal autonomic function. Transgenic animals lacking the $\alpha 3$ subunit have profound autonomic failure with prominent bladder distention, gastrointestinal dysmotility, and lack of pupillary light reflexes. ${ }^{11}$ Infants with a rare congenital mega- 
cystis-microcolon-intestinal hypoperistalsis syndrome also appear to lack $\alpha 3$-type AChR in enteric ganglia. ${ }^{12}$

Autoimmune autonomic ganglionopathy. An acquired form of autonomic failure in adults, autoimmune autonomic ganglionopathy (AAG), appears to be due to antibody-mediated disruption of synaptic transmission in autonomic ganglia. Over $50 \%$ of patients with the acute or subacute onset of diffuse autonomic failure have high titers of autoantibodies directed against the ganglionic ( $\alpha 3$-type) AChR. ${ }^{13}$ The clinical features of AAG (also known as autoimmune autonomic neuropathy, idiopathic autonomic neuropathy, or acute pandysautonomia) reflect widespread impairment of sympathetic and parasympathetic function with sparing of somatic nerve fibers. Symptoms evolve over a few days to a few months in previously healthy individuals of all ages and both sexes. About $15 \%$ of patients have paraneoplastic AAG usually associated with SCLC or thymoma. The other cases represent idiopathic organ-specific autoimmune disorders. A presumed antecedent viral infection is reported in about $60 \%$ of cases, with a flu-like illness or upper respiratory infection being the most frequent association. $^{14,15}$

Affected individuals typically experience orthostatic hypotension, inability to sweat, reduced lacrimation and salivation, bowel disturbances (ileus, abdominal colic, diarrhea, and constipation), atonic bladder, impotence, and a fixed heart rate. The most common symptoms, orthostatic hypotension and gastrointestinal dysfunction, each occur in more than $70 \%$ of patients. Tonic pupils that do not react to light, in the setting of these other autonomic symptoms, are highly suggestive of AAG. ${ }^{15,16}$ Serum ganglionic AChR antibody levels in AAG cases correlate with the severity of autonomic symptoms clinically and with the severity on laboratory testing of autonomic function. ${ }^{13,16} \mathrm{~A}$ decrease in antibody levels is associated with improvement in autonomic function.

Testing for ganglionic AChR antibodies has allowed the identification of additional cases with insidious symptom onset and gradual progression of disabling autonomic failure rather than the typical acute or subacute onset. Such chronic cases may be initially indistinguishable from degenerative forms of autonomic failure but can respond to treatment. ${ }^{17,18}$ Ganglionic AChR antibodies, at lower levels, may be found in $5 \%$ to $10 \%$ of patients with other disorders that have limited autonomic dysfunction, including postural tachycardia syndrome, idiopathic gastrointestinal dysmotility, or LambertEaton myasthenic syndrome. These antibodies are not found in control subjects. ${ }^{13,19}$ Although muscle and ganglionic AChR are structurally very similar, patients with AAG do not have muscle AChR antibodies except in rare cases where AAG coexists with myasthenia gravis. ${ }^{20}$
Likewise, patients with MG do not have ganglionic AChR antibodies. ${ }^{19}$

The clinical course of AAG is typically monophasic and patients may show spontaneous stabilization or recovery. However, the recovery is typically incomplete. ${ }^{14}$ Recurrences are uncommon. The mainstay of treatment is symptomatic management of autonomic failure including blood pressure support, bowel management, and supplemental moisture for dry eyes and mouth. Acetylcholinesterase inhibitors (pyridostigmine) are a novel therapy for autonomic failure which may improve standing blood pressure, restore salivation, and increase bowel motility by enhancing ganglionic synaptic transmission as well as muscarinic transmission at parasympathetic target organs. ${ }^{21}$ Immunomodulatory therapies, including plasma exchange or immunosuppressant drugs, especially as an early therapeutic intervention, are beneficial in some cases. ${ }^{18}$ This supports the concept that AAG is an antibody-mediated disorder.

Experimental AAG can be reproduced in rabbits by immunizing against the ganglionic $\mathrm{AChR},{ }^{22}$ and administration of ganglionic $\mathrm{AChR}$ antibodies to mice results in autonomic failure. ${ }^{23}$ These two observations confirm that AAG is an antibody-mediated disorder. Based on findings in animal models and in vitro studies, ganglionic AChR antibodies cause a direct effect on ganglionic AChR and produce impairment in ganglionic synaptic transmission by reducing the number of ganglionic AChR at autonomic synapses. ${ }^{22,24}$

\section{Voltage-gated (P/Q-type) calcium channels antibodies}

Voltage-gated calcium channels (VGCC) are membrane protein complexes formed by combinations of $\alpha 1$, $\beta, \gamma$, and $\alpha 2 \delta$ subunits. The VGCC on motor nerve terminals are of the $\mathrm{N}$ and $\mathrm{P} / \mathrm{Q}$ type. When the motor nerve terminal depolarizes, these channels mediate the increase in intracellular calcium, which triggers vesicle fusion and release of acetylcholine. Mutations in the P/Q-type (CACNA1a) VGCC have been implicated in neurological disorders such as familial hemiplegic migraine and spinocerebellar ataxia (see Pietroban ${ }^{25}$ and Kordasiewicz and Gomez ${ }^{26}$ ).

Lambert-Eaton syndrome. Antibodies against P/Qtype VGCC are found in more than $85 \%$ of patients with Lambert-Eaton myasthenic syndrome (LES). Antibodies against N-type VGCC are also found but are not specific for LES. About $60 \%$ of adult-onset cases are associated with SCLC, making this one of the most common paraneoplastic syndromes. LES is characterized by weakness and muscle fatigue in proximal limb muscles and reduced or absent tendon reflexes. Involvement of eye muscles is uncommon. Many patients have mild autonomic symptoms including dry mouth, constipation, and male impotence. Patients may show a very transient in- 
crease in muscle strength or recovery of reflexes after brief exercise (facilitation). On electrophysiologic assessment, the amplitude of compound muscle action potentials is low at rest and often increases dramatically in size during brief high frequency $(30-50 \mathrm{~Hz})$ stimulation of the motor nerve or immediately after a brief episode of isometric exercise (FIG. 1).

The pathogenicity of P/Q-type VGCC antibodies has been demonstrated in animal models of LES. Passive transfer of antibodies to mice produces typical neuromuscular transmission deficits ${ }^{27}$ and autonomic changes. ${ }^{28}$ Binding of antibodies reduces the number of functional VGCC on the motor nerve terminal. This results in a reduced release of acetylcholine with each nerve action potential and a reduction in the muscle endplate potential. During exercise or high frequency stimulation, calcium accumulates in the motor terminal and can transiently overcome this presynaptic deficit, correlating with the clinical and electrophysiologic evidence of facilitation.

Treatment of LES is similar to that of MG. Therapies that enhance neuromuscular junction transmission (acetylcholinesterase inhibitors) or reduce the levels of the pathogenic antibodies (plasma exchange, i.v. immunoglobulin, or immunosuppression) may be beneficial. The use of 3,4-diaminopyridine (a potassium channel antagonist) can also provide specific symptomatic benefit by prolonging the action potential in the motor nerve terminal and allowing additional calcium entry. ${ }^{29}$ An important aspect of the clinical management of paraneoplastic LES is detection and treatment of lung cancer. Most patients do not have a history of cancer at the time of their initial presentation, and the SCLC is often small and limited to the mediastinal lymph nodes. If initial computed tomography of the chest is unremarkable, close follow-up or additional imaging with metabolic positron emission tomography (PET) is important. ${ }^{30}$ Successful treatment of SCLC often leads to improvement in the symptoms of LES. ${ }^{29}$

Paraneoplastic cerebellar degeneration. P/Q-type VGCCs are not only present at the presynaptic motor nerve terminal but were, in fact, first identified in cerebellar Purkinje cells. In individual patients and clinical case series, LES is associated with cerebellar ataxia more often than expected by chance. ${ }^{31,32}$ Patients with ataxia and LES almost always have SCLC and high levels of P/Q-type VGCC antibodies.

Some patients with SCLC-associated cerebellar ataxia may have P/Q-type VGCC antibodies without any features of LES. ${ }^{33}$ Thus, VGCC antibodies are a serologic marker of paraneoplastic cerebellar degeneration associated with SCLC. Finding these antibodies should lead to a search for lung cancer as discussed above. At autopsy, several patients with these antibodies have shown a reduction in Purkinje cell number and reduction in P/Q- type VGCCs in the cerebellum. ${ }^{34}$ However, there is currently no evidence that serum VGCC antibodies can directly affect the function of cerebellar neurons, especially with an intact blood-brain barrier.

\section{Voltage-gated potassium channel antibodies}

Voltage-gated potassium channels (VGKC) are widely distributed in the central and peripheral nervous system and are important for the regulation of neuronal excitability. Over 70 genes encoding mammalian potassium channels have been identified, including eight members of the Kv1 (Shaker-type) voltage-dependent potassium channel family. The snake venom $\alpha$-dendrotoxin binds to three of the shaker-type VGKC; Kv1.1, 1.2, and 1.6. Envenomation causes muscle twitching, stiffness, and pain because of hyperexcitability of peripheral nerves. Episodic ataxia type 1 (EA1) is a rare autosomal dominant disorder caused by mutation in the Kv1.1 channel (see Rajakulendran et al. ${ }^{35}$ ). ${ }^{36}$ In addition to ataxic episodes, continuous myokymia (involuntary twitching of muscle) is a consistent feature in EA1. Antibodies against VGKC are associated with disorders with similar features of peripheral nerve hyperexcitability.

Neuromyotonia (Isaacs' syndrome). Autoimmune neuromyotonia (also known as Isaacs' syndrome) is an acquired disorder characterized by insidious onset of generalized muscle stiffness, continuous muscle twitching and undulation (myokymia), muscle hypertrophy and stiffness, weight loss, and hyperhidrosis. Encephalopathy, seizures, sleep disturbances, or behavioral changes may coexist with peripheral nerve hyperexcitability and may represent the effects of VGKC antibodies on neuronal excitability in the CNS. ${ }^{37,38}$ When the behavioral manifestations are severe, the patients may be designated as Morvan's syndrome (see below). Autoimmune neuromyotonia can coexist with MG or other autoimmune disorders and can occur as a paraneoplastic syndrome with thymoma or SCLC (Table 2). ${ }^{37-39}$

The electrophysiologic findings in patients with autoimmune neuromytonia are characteristic. There may be repetitive afterdischarges after the compound muscle action potential (FIG. 2), repetitive firing of $F$ waves, and high frequency activity (cramps) induced by repetitive nerve stimulation..$^{40}$ On the needle EMG examination, a wide variety of spontaneous motor unit activity is seen, including abundant fasciculations, myokymic discharges, neuromyotonic discharges, and voluntary motor units firing as doublets and triplets (FIG. 2). The activity persists during sleep. Much of the abnormal motor nerve activity appears to originate distally, at or near the motor nerve terminal. ${ }^{40}$

Milder forms of acquired peripheral nerve hyperexcitability may also be autoimmune channelopathies in some cases. Cramp-fasciculation syndrome, for example, is characterized by muscle aching, cramps, exercise intol- 
TABLE 2. Autoimmune Peripheral Nerve Hyperexcitability $(\mathrm{PNH})$

\begin{tabular}{lccc}
\hline Diagnosis & $\begin{array}{c}\text { VGKC } \\
\text { Antibody* }\end{array}$ & MG & Cancer (\%) \\
\hline $\begin{array}{l}\text { Neuromyotonia or } \\
\text { diffuse myokymia }\end{array}$ & $47 \%$ & $15 \%$ & $\begin{array}{c}27 \% \text { (thymoma or } \\
\text { SCLC) }\end{array}$ \\
CFS & $23 \%$ & $11 \%$ & $7 \%$ (thymoma) \\
$\begin{array}{l}\text { Normal controls } \\
\text { Thymoma } \\
\text { (without PNH) }\end{array}$ & $2 \%$ & & \\
\end{tabular}

CFS $=$ Cramp-fasciculation syndrome; VGKC $=$ voltage-gated potassium channels. $*$ Voltage-gated potassium channel antibodies detected using dendrotoxin receptor immunoprecipitation assay. Data compiled from references 37 and 38 .

erance, and visible fasciculations but does not have the more complex continuous muscle activity associated with neuromyotonia (Table 2). ${ }^{41}$ Painful cramps characteristically develop during rest after a period of exercise and may involve unusual muscles, such as the abdominal or pharyngeal muscles. Another rare presentation of autoimmune peripheral nerve hyperexcitability is rippling muscle syndrome. This disorder is characterized by painless waves of muscle contractions that may be electrically silent or associated with high frequency discharges (as in neuromyotonia). Most reported cases have been associated with $\mathrm{MG}^{38,42}$

About $45 \%$ of patients with neuromyotonia and $25 \%$ with cramp-fasciculation syndrome have antibodies against VGKC ( $\alpha$-dendrotoxin receptors). Antibodies against Kv1.6 and Kv1.2 appear to be most relevant because Kv1.6 is expressed on intramuscular axons close to the neuromuscular junction and $\mathrm{Kv} 1.2$ is expressed on the juxtaparanodal region of the axon. ${ }^{43}$ These VGKC normally serve to repolarize the axon and to prevent generation of repetitive action potentials especially as the wave of depolarization enters the terminal motor axon.

Diffuse neuromyotonia is usually disabling and warrants treatment. Symptomatic treatments with membrane stabilizing drugs (such as phenytoin, carbamazepine, gabapentin) are often effective and sufficient in milder cases. Similar treatments can be offered to patients with cramp-fasciculation syndrome. In more severe cases of autoimmune peripheral nerve hyperexcitability (especially those with VGKC autoantibodies), plasma exchange or intravenous immunoglobulin have been reported to produce rapid improvement. ${ }^{44,45}$ Some cases are monophasic and show spontaneous improvement, while many other patients require some form of maintenance therapy. Immunosuppressants (e.g., steroids, azathioprine, cyclophosphamide) have been used. ${ }^{39,46,47}$ The response to plasma exchange and immunosuppres- sion supports the concept that neuromyotonia is an antibody-mediated neurological disorder.

Antibodies from patients have been shown to cause a reduction in potassium currents in cultured cells $\mathrm{s}^{48-50}$ and can promote repetitive firing of action potentials in cultured dorsal root ganglia neurons (similar to the effects of potassium channel antagonists). ${ }^{44}$ Additionally, conventional passive transfer (administration of antibodies to mice) produces several effects that are subtle but consistent with nerve hyperexcitability due to potassium channel inhibition. ${ }^{44,45}$

Morvan's syndrome. Morvan's syndrome, first recognized over 100 years ago, consists of the combination of acquired neuromyotonia, autonomic hyperactivity, and fluctuating encephalopathy. Muscle twitching, stiffness, and hyperhidrosis are similar to Isaacs' syndrome, but autonomic dysfunction and sensory symptoms tend to be more prominent. ${ }^{51}$ Abnormal cognition is charac-
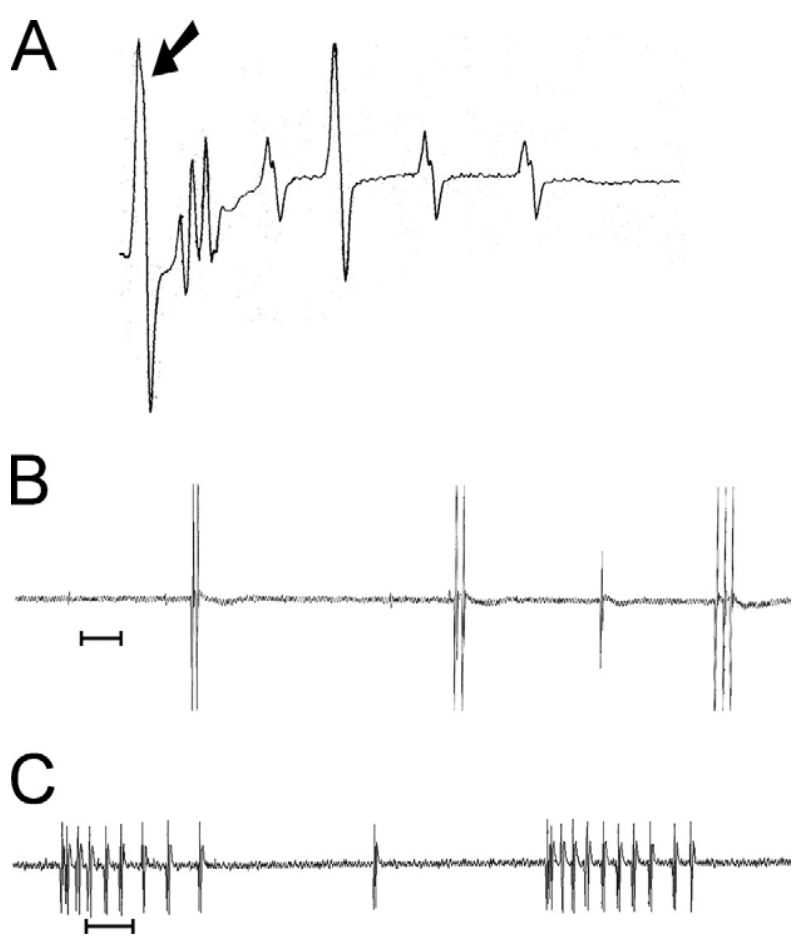

FIG. 2. Electrophysiologic features of autoimmune neuromyotonia. (A) Peroneal nerve motor response in a patient with Isaacs syndrome (recorded over the extensor digitorum brevis muscle with stimulation at the ankle, scale $=500 \mu \mathrm{V}$ and $10 \mathrm{~ms}$ per division). The initial compound muscle action potential response (arrow) is followed by multiple afterdischarges some of which have the same morphology. The afterdischarges vary in timing and appearance with each stimulation (response to a single stimulation is shown). (B) Single and groups of doublet or triplet fasciculations in a patient with cramp-fasciculation syndrome (first dorsal interosseous muscle, scale bar $=200 \mathrm{~ms} ; 50 \mu \mathrm{V}$ / division). (C) Repetitive spontaneous firing of a motor unit potential (myokymic discharges) in a patient with Isaacs syndrome (deltoid muscle, scale bar $=100 \mathrm{~ms} ; 200 \mu \mathrm{V} /$ division). The frequency of motor unit firing within the burst is $40 \mathrm{~Hz}$. Neuromyotonic discharges appear as longer bursts with higher intraburst frequency (as high as $250 \mathrm{~Hz}$ ). 


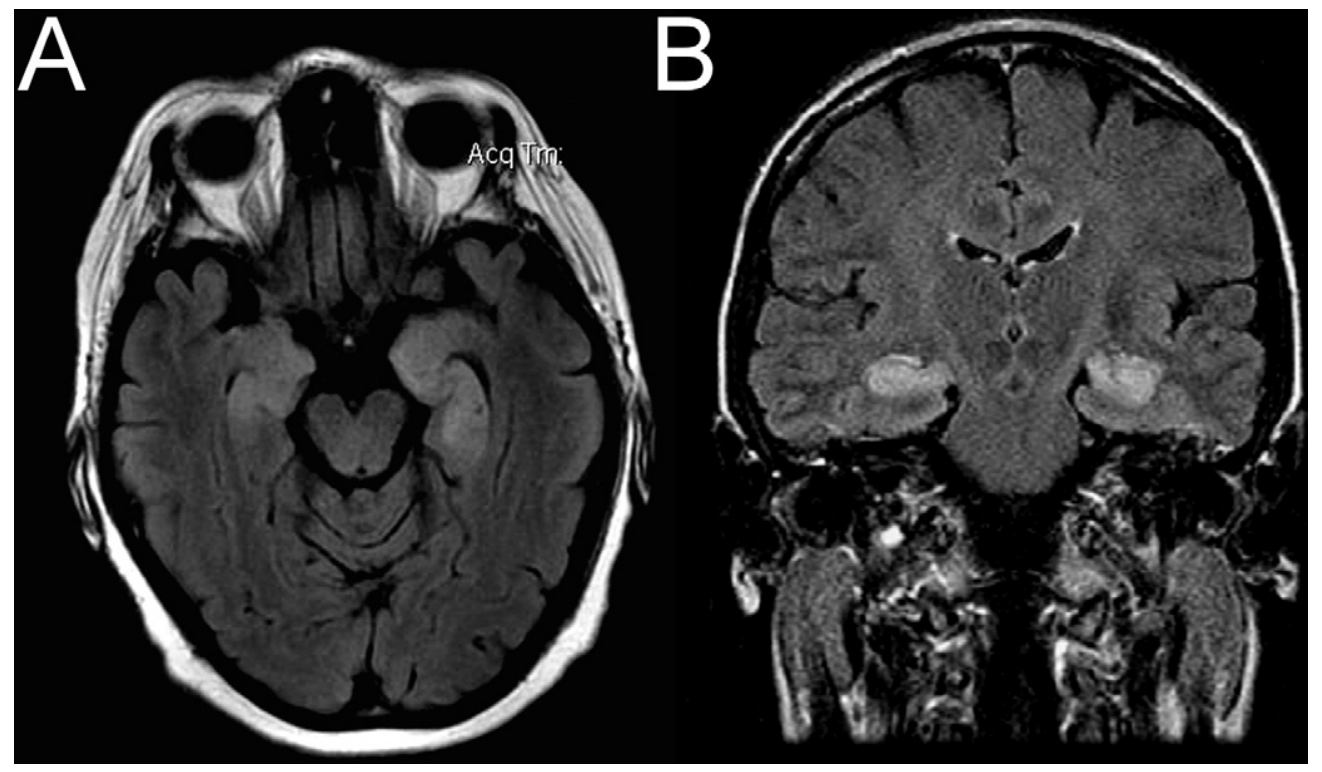

FIG. 3. Autoimmune limbic encephalitis. Magnetic resonance imaging (MRI) abnormalities consist of asymmetric increased T2 and FLAIR signal in the mesial temporal lobes with minimal or no contrast enhancement. In a patient with autoimmune limbic encephalitis associated with voltage-gated potassium channel antibodies, typical changes are seen on axial FLAIR MRI (A) and coronal FLAIR MRI (B). These findings are indistinguishable from those seen in paraneoplastic limbic encephalitis.

terized by episodes of disorientation with prominent hallucinations and severe short-term memory dysfunction. The sleep disturbance is quite severe. In some cases, formal sleep studies document a complete absence of sleep (which may lead to a misdiagnosis of fatal familial insomnia). When sleep does occur, dramatic dream enactment behavior may be seen along with significant abnormalities of sleep architecture. Brain MRI shows no significant abnormalities, which helps differentiate Morvan's syndrome from limbic encephalitis. ${ }^{52,53}$

Among the cases described in English literature, over $90 \%$ of patients are male. Like neuromyotonia, Morvan's syndrome is seen in association with MG, thymoma, or SCLC. Most patients have VGKC antibodies. ${ }^{51,53,54}$ Both the central and the neuromuscular symptoms improve with immunomodulatory treatments including plasma exchange, suggesting that this is also an antibody-mediated disorder. ${ }^{46,53}$

Limbic encephalitis. More recently, VGKC antibodies were identified in several individual patients with cognitive changes who did not have peripheral nerve hyperexcitability, ${ }^{55-57}$ and two larger case series have defined this entity as a distinct clinical syndrome. ${ }^{58,59}$ The clinical and radiologic findings at presentation in these patients are indistinguishable from those of paraneoplastic limbic encephalitis, consisting of subacute cognitive impairment with behavioral changes and temporal lobe seizures, high T2 and FLAIR signal in the mesial temporal lobes (FIG. 3), and temporal lobe electroencephalographic abnormalities.

Unique features of limbic encephalitis with VGKC antibodies are the frequent association with hyponatre- mia, a strong male predominance, and often dramatic response to treatment with high dose steroids or plasma exchange. ${ }^{58,59}$ Patients with paraneoplastic limbic encephalitis associated with lung cancer or thymoma have identical symptoms and may have VGKC antibodies. However, when limbic encephalitis is associated with very high levels of VGKC antibodies, no other paraneoplastic neurological symptoms, and no other paraneoplastic autoantibodies, most cases are not paraneoplastic. Unlike those with paraneoplastic limbic encephalitis, patients with VGKC antibodies often improve dramatically after treatment with steroids or plasma exchange. The MRI mesial temporal lobe signal abnormalities resolve and VGKC antibodies titers fall with successful treatment.

The rapid response to plasma exchange suggests a direct role of the antibodies. ${ }^{59}$ Temporal lobe seizures and memory impairment could be explained by inhibition of potassium channels in the hippocampus. Different fine selectivity of the VGKC antibodies may explain the manifestations of peripheral nerve hyperexcitability in some patients and limbic encephalitis in others. ${ }^{43}$ However, further studies are needed to prove that VGKC antibodies can enter the CNS and directly affect neuronal function. It is still possible that these antibodies are important as a diagnostic marker of autoimmunity but not directly involved in the pathogenesis of the disorder.

VGKC antibodies have also been found in patients with intractable temporal lobe epilepsy even if the cognitive and behavioral features of limbic encephalitis are not present. ${ }^{60}$ Autoimmune channelopathy may ulti- 
mately prove to be an important and potentially treatable cause of acquired idiopathic temporal epilepsy.

\section{Other autoimmune channelopathies}

Intractable epilepsy. Rasmussen's encephalitis is a severe form of intractable childhood epilepsy and encephalopathy that is often restricted to one hemisphere. Antibodies against one subtype of neuronal AMPA-type glutamate receptor (GluR3) were first identified in these patients after the serendipitous observation that rabbits immunized against GluR3 developed seizures and encephalitis. ${ }^{61}$ Glutamate receptors are ligand-gated cation channels that are responsible for much of the excitatory synaptic transmission in the brain.

GluR3 antibodies have also been reported in adult patients with intractable epilepsy, but the significance and reproducibility of serologic testing is uncertain. ${ }^{62}$ Current evidence suggests that the pathogenesis of Rasmussen's encephalitis is mediated by T-cell immunity. ${ }^{63}$ Thus, the significance of GluR3 antibodies in the pathophysiology of encephalitis and epilepsy remains unproven.

In two other cases of Rasmussen's encephalitis, there was evidence of serum antibodies that inhibited the function of neuronal $\alpha 7$-type AChR. ${ }^{64}$ These $\alpha 7$ AChR are abundant in the brain and appear to be important in modulation of synaptic transmission. These channels may be another emerging target for autoimmune channelopathy.

Neuropsychiatric lupus. Independent of the rare complications of lupus cerebritis and vasculitis, patients with systemic lupus erythematosus (SLE) often have a variety of neuropsychiatric symptoms. These can include headache, short-term memory impairment, depression, and psychosis. There appears to be no relationship between these symptoms and the presence or titer of serum antinuclear antibodies or antibodies against DNA or other identifiable nuclear or cytoplasmic antigens. However, some of the anti-DNA antibodies in SLE patients appear to cross-react with NR2-type (NMDA) glutamate receptors. ${ }^{65}$ These ligand-gated ion channels are recognized to have a central role in many forms of synaptic plasticity. The presence of elevated levels of NR2 antibodies are associated with the presence of depression and memory deficits in SLE patients. ${ }^{66}$ However, these associations are weak, and the antibodies may be found in patients with other disorders as well as some healthy control subjects. The clinical utility of NR2 antibody studies remains to be determined.

Injection of NR2A antibodies into the mouse brain or immunization against NR2A peptides (along with disruption of the blood-brain barrier) leads to deposition of IgG in the hippocampus and loss of hippocampal pyramidal neurons. These animals demonstrated deficits on behavioral tasks consistent with impaired learning. ${ }^{67}$
Neuromyelitis optica. Humoral autoimmunity directed against other membrane channels may also be important. Many patients with neuromyelitis optica (NMO, a severe inflammatory demyelinating disorder of the optic nerves and spinal cord) have antibodies against aquaporin-4, a membrane water channel found in the CNS. ${ }^{68}$ Aquaporin antibodies help to identify patients with NMO and direct treatment. NMO may represent a novel form of autoimmune channelopathy.

\section{CONCLUSIONS}

Autoimmune channelopathies are a group of neurological disorders associated with antibodies against ligand- or voltage-gated ion channels. In several disorders (myasthenia gravis, Lambert-Eaton syndrome, neuromyotonia, and autoimmune autonomic ganglionopathy), there is good evidence that antibodies alter synaptic function or neuronal excitability by directly inhibiting ion channel function. The proven antibody-mediated channelopathies are all peripheral nervous system disorders. More recently, ion channel antibodies have been identified in patients with certain CNS disorders. It is still unclear if these antibodies can gain access to the CNS and directly cause ion channel dysfunction. Nevertheless, the antibodies may be important diagnostic markers to identify patients with an autoimmune, and potentially treatable, disorder. Treatment of autoimmune channelopathies includes drugs that help restore normal synaptic transmission (such as acetylcholinesterase inhibitors for myasthenia gravis) or reduce neuronal excitability (such as anticonvulsants for neuromytonia). More importantly, treatments to remove pathogenic antibodies (plasma exchange) or reduce the autoimmune response (steroids or immunosuppression) are effective in several of these disorders. Even though the autoimmune channelopathies are uncommon, they are important to consider because of the potential treatment implications. Testing for well characterized ion channel antibodies is now commercially available. Future studies will likely lead to identification of other ion channel antibodies and other autoimmune neurological disorders.

Acknowledgments: Studies on autoimmune autonomic ganglionopathy are supported by National Institutes of Health, Grant Nos. R01NS48077 and P50NS32353, and by the University of Texas Southwestern Medical Center.

\section{REFERENCES}

1. Drachman D. Myasthenia gravis. N Engl J Med 1994;330:17971810.

2. Albert ML, Darnell RB. Paraneoplastic neurological degenerations: keys to tumour immunity. Nat Rev Cancer 2004;4:36-44.

3. Oguro-Okano M, Griesmann GE, Wieben ED, Slaymaker SJ, Snutch TP, Lennon VA. Molecular diversity of neuronal-type calcium channels identified in small cell lung carcinoma. Mayo Clin Proc 1992;67:1150-1159. 
4. Sciamanna MA, Griesmann GE, Williams CL, Lennon VA. Nicotinic acetylcholine receptors of muscle and neuronal (alpha7) types coexpressed in a small cell lung carcinoma. J Neurochem 1997;69:2302-2311.

5. Drachman DB. How to recognize an antibody-mediated autoimmune disease: criteria. In: Waksman BH, ed. Immunologic mechanisms in neurologic and psychiatric disease. New York: Raven Press; 1990:183-186.

6. Engel AG. The therapy of congenital myasthenic syndromes. Neurotherapeutics 2007;4:252-257.

7. Vernino S, Lennon VA. Autoantibody profiles and neurological correlations of thymoma. Clin Cancer Res 2004;10:7270-7275.

8. Lambert EH, Lindstrom JM, Lennon VA. End-plate potentials in experimental autoimmune myasthenia gravis in rats. Ann N Y Acad Sci 1976;274:300-318.

9. Patrick J, Lindstrom J. Autoimmune response to acetylcholine receptors. Science 1973;180:871-872.

10. Lindstrom JM, Engel AG, Seybold ME, Lennon VA, Lambert EH. Pathological mechanisms in experimental autoimmune myasthenia gravis. II. Passive transfer of experimental autoimmune myasthenia gravis in rats with anti-acetylcholine receptor antibodies. J Exp Med 1976;144:739-753.

11. Xu W, Gelber S, Orr-Urtreger A, et al. Megacystis, mydriasis, and ion channel defect in mice lacking the alpha3 neuronal nicotinic acetylcholine receptor. Proc Natl Acad Sci U S A 1999;96:57465751.

12. Richardson CE, Morgan JM, Jasani B, et al. Megacystis-microcolon-intestinal hypoperistalsis syndrome and the absence of the alpha3 nicotinic acetylcholine receptor subunit. Gastroenterology 2001;121:350-357.

13. Vernino S, Low PA, Fealey RD, Stewart JD, Farrugia G, Lennon VA. Autoantibodies to ganglionic acetylcholine receptors in autoimmune autonomic neuropathies. N Engl J Med 2000;343:847855.

14. Suarez GA, Fealey RD, Camilleri M, Low PA. Idiopathic autonomic neuropathy: clinical, neurophysiologic, and follow-up studies on 27 patients. Neurology 1994;44:1675-1682.

15. Sandroni P, Vernino S, Klein CM, et al. Idiopathic autonomic neuropathy: comparison of cases seropositive and seronegative for ganglionic acetylcholine receptor antibody. Arch Neurol 2004;61: $44-48$.

16. Klein CM, Vernino S, Lennon VA, et al. The spectrum of autoimmune autonomic neuropathies. Ann Neurol 2003;53:752-758.

17. Goldstein D, Holmes C, Dendi R, Li S-T, Brentzel S, Vernino S. Pandysautonomia associated with impaired ganglionic neurotransmission and circulating antibody to the neuronal nicotinic receptor. Clin Auton Res 2002;12:281-285.

18. Schroeder C, Vernino S, Birkenfeld AL, et al. Plasma exchange for primary autoimmune autonomic failure. N Engl J Med 2005;353: $1585-1590$

19. Vernino S, Adamski J, Kryzer TJ, Fealey RD, Lennon VA. Neuronal nicotinic ACh receptor antibody in subacute autonomic neuropathy and cancer-related syndromes. Neurology 1998;50:18061813.

20. Vernino S, Cheshire WP, Lennon VA. Myasthenia gravis with autoimmune autonomic neuropathy. Auton Neurosci 2001;88:187192.

21. Singer W, Opfer-Gehrking TL, McPhee BR, Hilz MJ, Bharucha AE, Low PA. Acetylcholinesterase inhibition: a novel approach in the treatment of neurogenic orthostatic hypotension. J Neurol Neurosurg Psychiatry 2003;74:1294-1298.

22. Lennon VA, Ermilov LG, Szurszewski JH, Vernino S. Immunization with neuronal nicotinic acetylcholine receptor induces neurological autoimmune disease. J Clin Invest 2003;111:907-913.

23. Vernino S, Ermilov LG, Sha L, Szurszewski JH, Low PA, Lennon VA. Passive transfer of autoimmune autonomic neuropathy to mice. J Neurosci 2004;24:7037-7042.

24. Vernino S, Low PA, Lennon VA. Experimental autoimmune autonomic neuropathy. J Neurophysiol 2003;90:2053-2059.

25. Pietroban D. Familial hemiplegic migraine. NeuroRx2007;4.

26. Kordasiewicz HB, Gomez CM. Molecular pathogenesis of spinocerebellar ataxia type 6 (SCA6). Neurotherapeutics 2007;4:285294.
27. Lambert EH, Lennon VA. Selected IgG rapidly induces LambertEaton myasthenic syndrome in mice: complement independence and EMG abnormalities. Muscle Nerve 1988;11:1133-1145.

28. Waterman S, Lang B, Newsom-Davis J. Effect of Lambert-Eaton myasthenic syndrome antibodies on autonomic neurons in the mouse. Ann Neurol 1997;42:147-156.

29. McEvoy KM. Diagnosis and treatment of Lambert-Eaton myasthenic syndrome. Neurol Clin 1994;12:387-399.

30. Rees JH, Hain SF, Johnson MR, et al. The role of [18F]fluoro-2deoxyglucose-PET scanning in the diagnosis of paraneoplastic neurological disorders. Brain 2001;124:2223-2231.

31. Lennon VA, Kryzer TJ, Griesmann GE, et al. Calcium-channel antibodies in the Lambert-Eaton syndrome and other paraneoplastic syndromes. N Engl J Med 1995;332:1467-1474.

32. Clouston PD, Saper CB, Arbizu T, et al. Paraneoplastic cerebellar degeneration. III. Cerebellar degeneration, cancer, and the Lambert-Eaton myasthenic syndrome. Neurology 1992;42:1944-1950.

33. Graus F, Lang B, Pozo-Rosich P, Saiz A, Casamitjana R, Vincent A. P/Q type calcium-channel antibodies in paraneoplastic cerebellar degeneration with lung cancer. Neurology 2002;59:764-766.

34. Fukuda T, Motomura M, Nakao Y, et al. Reduction of P/Q-type calcium channels in the postmortem cerebellum of paraneoplastic cerebellar degeneration with Lambert-Eaton myasthenic syndrome. Ann Neurol 2003;53:21-28.

35. Rajakulendran S, Schorge S, Kullmann DM, Hanna MG. Neurotherapeutics 2007;4:258-266.

36. Zuberi SM, Eunson LH, Spauschus A, et al. A novel mutation in the human voltage-gated potassium channel gene (Kv1.1) associates with episodic ataxia type 1 and sometimes with partial epilepsy. Brain 1999;122:817-825.

37. Hart IK, Maddison P, Newsom-Davis J, Vincent A, Mills KR. Phenotypic variants of autoimmune peripheral nerve hyperexcitability. Brain 2002;125:1887-1895.

38. Vernino S, Lennon VA. Ion channel and striational antibodies define a continuum of autoimmune neuromuscular hyperexcitability. Muscle Nerve 2002;26:702-707.

39. Newsom-Davis J, Mills KR. Immunological associations of acquired neuromyotonia (Isaacs' syndrome) report of five cases and literature review. Brain 1993;116:453-469.

40. Auger RG. AAEM Minimonograph \#44: diseases associated with excess motor unit activity. Muscle Nerve 1994;17:1250-1263.

41. Tahmoush A, Alonso R, Tahmoush G, Heiman-Patterson T. Cramp-fasciculation syndrome: a treatable hyperexcitable peripheral nerve disorder. Neurology 1991;41:1021-1024.

42. Ansevin C, Agamanolis D. Rippling muscles and myasthenia gravis with rippling muscles. Arch Neurol 1996;53:197-199.

43. Kleopa KA, Elman LB, Lang B, Vincent A, Scherer SS. Neuromyotonia and limbic encephalitis sera target mature Shaker-type $\mathrm{K}+$ channels: subunit specificity correlates with clinical manifestations. Brain 2006;129:1570-1584.

44. Shillito P, Molenaar PC, Vincent A, et al. Acquired neuromyotonia: evidence for autoantibodies directed against $\mathrm{K}+$ channels of peripheral nerves. Ann Neurol 1995;38:714-722.

45. Sinha S, Newsom-Davis J, Mills K, Byrne N, Lang B, Vincent A. Autoimmune aetiology for acquired neuromyotonia (Isaacs' syndrome). Lancet 1991;338:75-77.

46. Madrid A, Gil-Peralta A, Gil-Neciga E, Gonzalez J, Jarrin S. Morvan's fibrillary chorea: remission after plasmapheresis. J Neurol 1996;243:350-353

47. Riche G, Trouillas P, Bady B. Improvement of Isaacs' syndrome after treatment with azathioprine. J Neurol Neurosurg Psychiatry 1995;59:448.

48. Tomimitsu H, Arimura K, Nagado T, et al. Mechanism of action of voltage-gated $\mathrm{K}+$ channel antibodies in acquired neuromyotonia. Ann Neurol 2004;56:440-444.

49. Hart IK, Waters C, Vincent A, et al. Autoantibodies detected to expressed potassium channels are implicated in neuromyotonia. Ann Neurol 1997;41:238-246.

50. Arimura K. Antibodies directed to voltage-gated potassium channels in sera from acquired neuromyotonia and related disorders [in Japanese]. Rinsho Shinkeigaku 1999;39:1235-1236.

51. Liguori R, Vincent A, Clover L, et al. Morvan's syndrome: peripheral and central nervous system and cardiac involvement with 
antibodies to voltage-gated potassium channels. Brain 2001;124: 2417-2426.

52. Lawn ND, Westmoreland BF, Kiely MJ, Lennon VA, Vernino S. Clinical, magnetic resonance imaging, and electroencephalographic findings in paraneoplastic limbic encephalitis. Mayo Clin Proc 2003;78:1363-1368.

53. Josephs KA, Silber MH, Fealey RD, Nippoldt TB, Auger RG, Vernino S. Neurophysiologic studies in Morvan syndrome. J Clin Neurophysiol 2004;21:440-445.

54. Barber PA, Anderson NE, Vincent A. Morvan's syndrome associated with voltage-gated $\mathrm{K}+$ channel antibodies. Neurology 2000; 54:771-772.

55. Buckley C, Oger J, Clover L, et al. Potassium channel antibodies in two patients with reversible limbic encephalitis. Ann Neurol 2001;50:73-78.

56. Schott JM, Harkness K, Barnes J, della Rocchetta AI, Vincent A, Rossor MN. Amnesia, cerebral atrophy, and autoimmunity. Lancet 2003;361:1266. [Erratum. Lancet 2004;363:86].

57. Pozo-Rosich P, Clover L, Saiz A, Vincent A, Graus F. Voltagegated potassium channel antibodies in limbic encephalitis. Ann Neurol 2003;54:530-533.

58. Thieben MJ, Lennon VA, Boeve BF, Aksamit AJ, Keegan M, Vernino S. Potentially reversible autoimmune limbic encephalitis with neuronal potassium channel antibody. Neurology 2004;62: $1177-1182$.

59. Vincent A, Buckley C, Schott JM, et al. Potassium channel antibody-associated encephalopathy: a potentially immunotherapy-responsive form of limbic encephalitis. Brain 2004;127:701-712.
60. McKnight K, Jiang Y, Hart Y, et al. Serum antibodies in epilepsy and seizure-associated disorders. Neurology 2005;65:1730-1736.

61. Rogers S, Andrews P, Gahring L, et al. Autoantibodies to glutamate receptor GluR3 in Rasmussen's encephalitis. Science 1994; 265:648-651.

62. Mantegazza R, Bernasconi P, Baggi F, et al. Antibodies against GluR3 peptides are not specific for Rasmussen's encephalitis but are also present in epilepsy patients with severe, early onset disease and intractable seizures. J Neuroimmunol 2002;131:179-185.

63. Bien CG, Bauer J. T-cells in human encephalitis. NeuroMolecular Med 2005;7:243-254.

64. Watson R, Jepson JE, Bermudez I, et al. Alpha7-acetylcholine receptor antibodies in two patients with Rasmussen encephalitis. Neurology 2005;65:1802-1804.

65. DeGiorgio LA, Konstantinov KN, Lee SC, Hardin JA, Volpe BT, Diamond B. A subset of lupus anti-DNA antibodies cross-reacts with the NR2 glutamate receptor in systemic lupus erythematosus. Nat Med 2001;7:1189-1193.

66. Omdal R, Brokstad K, Waterloo K, Koldingsnes W, Jonsson R, Mellgren SI. Neuropsychiatric disturbances in SLE are associated with antibodies against NMDA receptors. Eur J Neurol 2005;12: 392-398.

67. Kowal C, DeGiorgio LA, Nakaoka T, et al. Cognition and immunity; antibody impairs memory. Immunity 2004;21:179-188.

68. Lennon VA, Kryzer TJ, Pittock SJ, Verkman AS, Hinson SR. IgG marker of optic-spinal multiple sclerosis binds to the aquaporin-4 water channel. J Exp Med 2005;202:473-477. 